\title{
Potentials of a Place as Leaders for Prioritizing the Adjustment of Public Spaces within a Hierarchy
}

\author{
Alena Bindzárová \\ Institute of Urban Design and Planning, Faculty of Architecture, Slovak University of Technology, Bratislava 81245, Slovakia
}

\begin{abstract}
The article gives a view over a part of a research that has been started on public spaces as a shared wealth of different qualities and uses. Introduction explores the capital of Slovakia a little bit in the sense of urban structure and historical consequences. The issue is currently solved by several members (academics, officials, NGOs (non-governmental organizations)) focusing on the same thing from slightly different aspects. Therefore, qualities and characteristics of an open space are put into closer look in the main text body part. Single tools working with individual features describe the up-to-date situation in the Bratislava city center. It is assumed that they could be used for whole city and other cities as well, what would bring an overall look at towns and cities in Slovakia. Features and findings are expressed in map and in simplified graphic schemes. Findings include mutual effects and consequences between role of a space in the city as a cultural phenomenon, its physical surrounding and people flowing daily through it. Finally, advices and prioritization could be formed for the city itself as a self-governing subject to improve its "inner-outer" qualities.
\end{abstract}

Key words: Public space, quantificators, urban design.

\section{Introduction}

This article focuses on current state of public spaces (Fig. 1) and on options and possible directions, considering up-to-date trends in topic observed elsewhere abroad [1-3].

Bratislava is capital of Slovakia since the independence declaration in 1993. It takes the west most position in the country of a longitudinal shape leading from east to west (around $500 \mathrm{~km}=310 \mathrm{mi}$ ). The capital city population of 300,000 exceeds up to nearly 500,000 with surrounding settlements and attached former rural, now urbanized areas and newly established very small towns also. All these suburban areas consist of daily commuters arriving to city business centers, schools and universities inside the city and to industrial grounds in the outer city. Bratislava has a great history; it was a coronation town during era of Austrian-Hungarian Empire and we can find here a typical medieval historical city core. This middle is surrounded by a late 19th century and

Corresponding author: Alena Bindzárová, M.Sc., research fields: urban design and architecture. interwar era urban blocks, followed by mass housing estates - a legacy of the socialism and communism since 1950 s to 1980 s. The last "ring" is formed by the mentioned suburban areas and villages-towns. Open public spaces have their typical characteristics bearing the information of location and about history. In general, disfunctions and low qualities can be named as features of these city elements, although the city possesses strong genius loci [4].

The paper is trying to look closely at the problems, weaknesses and mute strengths of our urban environment. Squares as defined, named and spatially-recognizable (not always) volumes of air, of unbuilt space are the subject of an analyses. There are 20 squares in the old town compared.

The data and tactics are tools of a cooperation between the Faculty of Architecture, Slovak University of Technology and the capital of Slovakia-Bratislava, Office of Chief Architect. It must be stated from the very beginning, that approaches are clearly different. However, speaking of one issue and aiming at one goal. Whereas the academic point of view is more still and has more time to explore the ideals, values, context, 


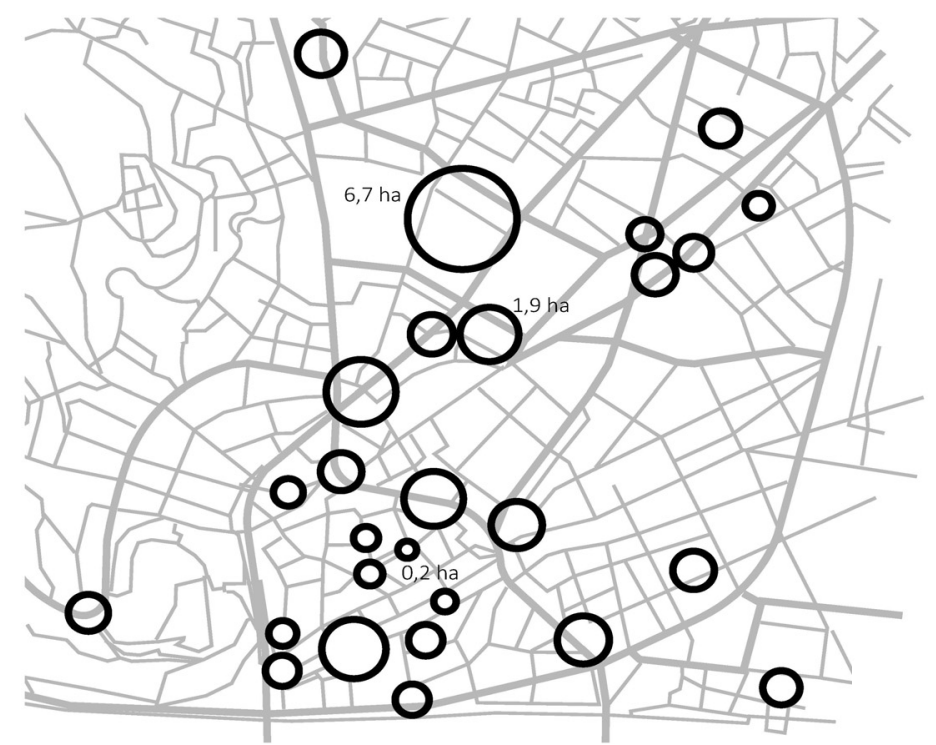

Fig. 1 Size of public spaces.

culture and arts, the city officials and their teams are under the pressure of making the work faster and more effective (taking the effect in the place).

The first goal of the paper is to highlight the issue that is emerging here in Slovakia only in last few years, to sketch possible first steps as a small part of a solution.

The second goal is to push forward the theme of public spaces by approaches and solutions on certain undergone pre-researches (needing to be advanced), to give a more detailed look at this question, take into account the gathered data and facts with publicly received reality.

The third goal is to explain the tools used for describing the places, considering the pedestrian, façades openings and reuse of buildings.

Basically the tools, so-called potentials in the title, stand for urban design, architectural, sociological and cultural characteristics visualized in a way that they act like quantificators with a rate expressing the ratio of future development of an element (a place) regarding the above mentioned goals.

\section{Core}

In this article, the big and small goals should be defined. The first group speaks of trying to reintegrate the multiplicity and hierarchy of public spaces whole showing phenomena of society's life in its own environment. Supporting this life in many aspects is one of the wanted effects.

There are smaller goals such as pre-sketch simply and logically the optional way of adjusting the public space. By words "simply and logically", a readable rendering elements are meant, which are to express selected features and it is worth working with them as long as they already are being used or are new. By the "way of adjusting the public space", it is to be underlined that there are rules for existing and for planned and newly built structures, too.

Demands of a man and society can be easily classified into three groups. The importance of each is considerable, although the real state of our surroundings does not meet the ideas of nice livable world. The very first is walkability and safety; The next group is made up of interaction (the presence of a location and also quality of a spot for interaction), public interest (attractiveness and hostility, the image of a place in the citizens' and visitors' memory); The last group consists of identity and city logic (natural hierarchy supported by the readability and fluidity of flowing demonstration of living polycentric urbanized area).

As mentioned before about the potentials in the 
research, the next are taken as being useful: (1) expansion of the pedestrian areas and reduction of motorized transport in the majority of city; (2) opening the façades of the surrounding buildings to the public; (3) reusing the existing structures and thus supporting the intensification of city use.

The research itself should be described in two phases as a group of tools and, comparison and correlation are needed: (1) Mapped tools are: academic (defined and used by the Faculty of Architecture), such as importance (Fig. 2), and identity of a city and place declared by several sub-tools like accessibility, green areas, compactness, lost and kept streets, passageways, parterre, composition; (2) Tools mapped, defined and used by the chief architect workgroup to render the situation describe the walkability of a place - percentage of pedestrian areas, cumulation grouping and parterre activity, and to describe the potential of buildings enclosing the squares percentage of active façades.

\subsection{Importance}

The following was evaluated in order to make a list of public and its socio-cultural hierarchy: history, public and historically important buildings in a square, historical events and current status in the collective mind of Slovaks and Bratislava's citizens. In the study of Ref. [5], squares of national/international meaning, 12 squares of city/regional importance and one locally important square have been included. The map of Fig. 2 shows the real position of squares within the map of old town and central urban area, on the right side, there is a transcription bearing the information about the importance and leaving the aspect of a size of a public space behind.

\subsection{Percentage of Pedestrian Areas (within Walkability)}

A square (Fig. 3) represents a meeting point where different directions with its own life come to one node and mix together on a typically bigger open space with several aims to be claimed. With the motorized transportation prevailing in most of the cities today, a percentage of surface dedicated to pedestrian was the interesting element for us. In the Fig. 1, the ratio of pedestrian areas (black) and all other kinds of traffic and public life — roads, bike lanes, tram lanes, lawns, and inaccessible places can be seen. As will be later explained in the findings, some of squares are nearly wholly dedicated to walking movement speed of a pedestrian. Nearly half space has only something around $1 / 4$ walkable surfaces which is quite stressing for the urban citizenship.

\subsection{Percentage of Active Façades}

The above sub-chapters have explained the presence of street volume scheme and the principle of mapping active parterre. The active façades (Fig. 4) are those, that have openings, perforations and windows reaching the height $+100 \mathrm{~cm}$ above ground to $160 \mathrm{~cm}$ at least (blue in Fig. 5). It means if a window starts too high or ends too close to bottom/surface, it was not counted in (black in Fig. 5). However, the map included perforations that are not currently used, but according to physical structure, they have potential to be reused in future (pale blue in Fig. 5).

\subsection{Importance, Percentage of Pedestrian Areas and Percentage of Active Façades}

The comparison and correlation of observed selected factors considering phased adjustment changes and humanizing process prepared by the city council cooperating with the publicity. The importance, percentage of pedestrian areas and percentage of active façades (Figs. 5 and 6) lead our thinking to a prioritization. Thus in what order and in which way the place can be more livable, how the quality (several kinds of qualities) can be enhanced in the sense of physical built environment, and in the sense of predicting and forming the future via regulations and advices. 

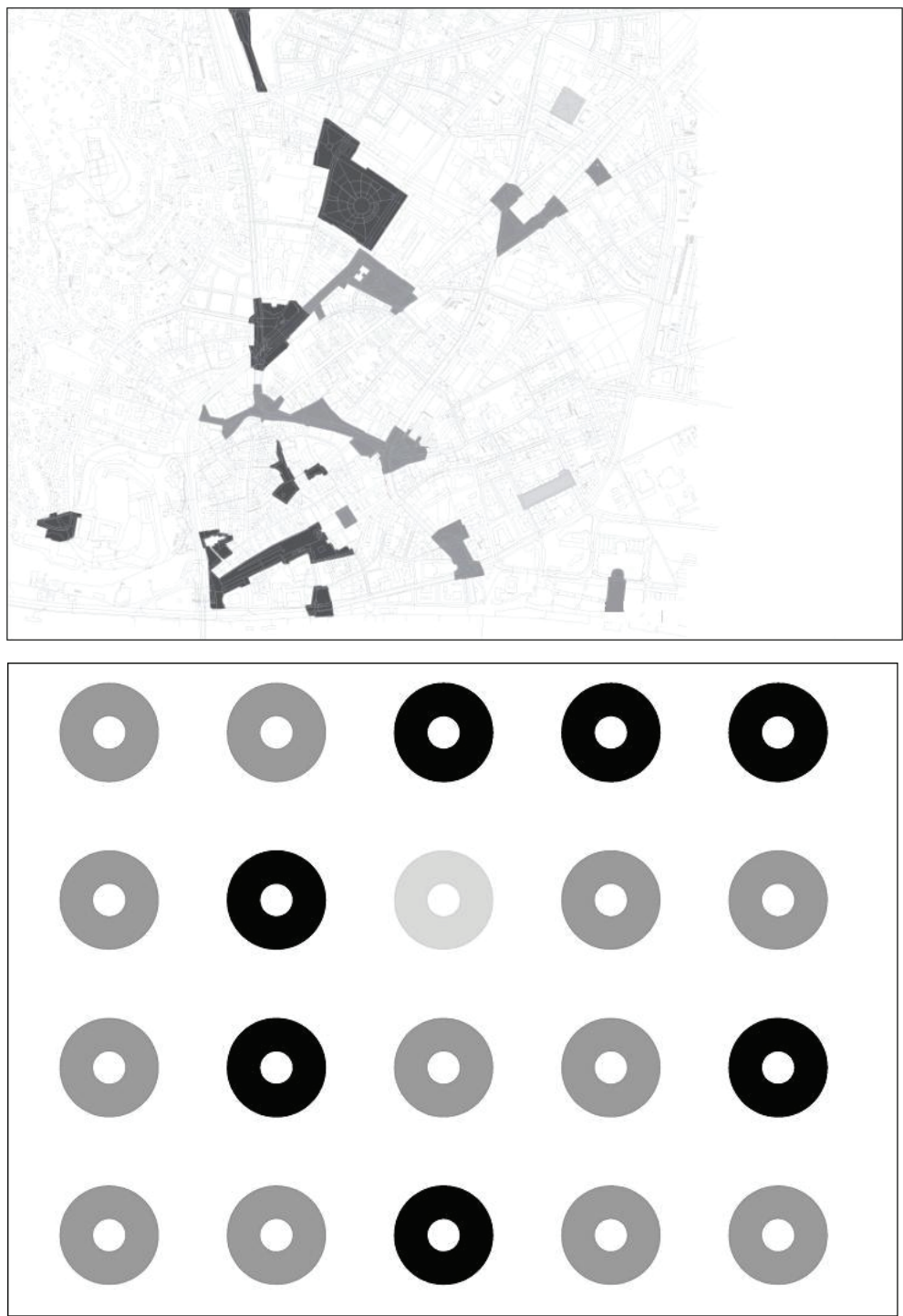

Fig. 2 Importance of a public space (socio-cultural aspect) [6].

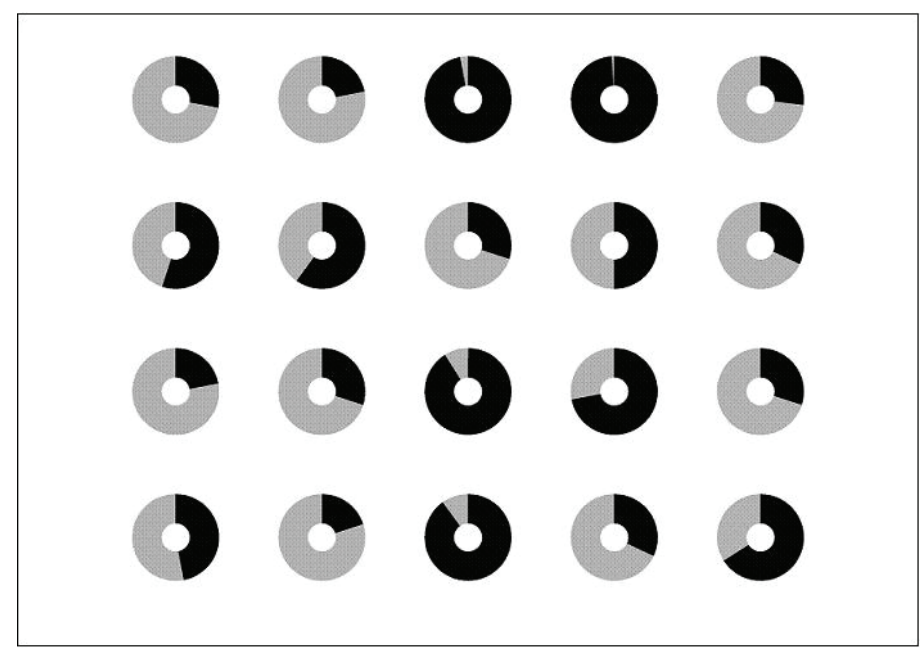

Fig. 3 Percentage of pedestrian (walkable) areas. 


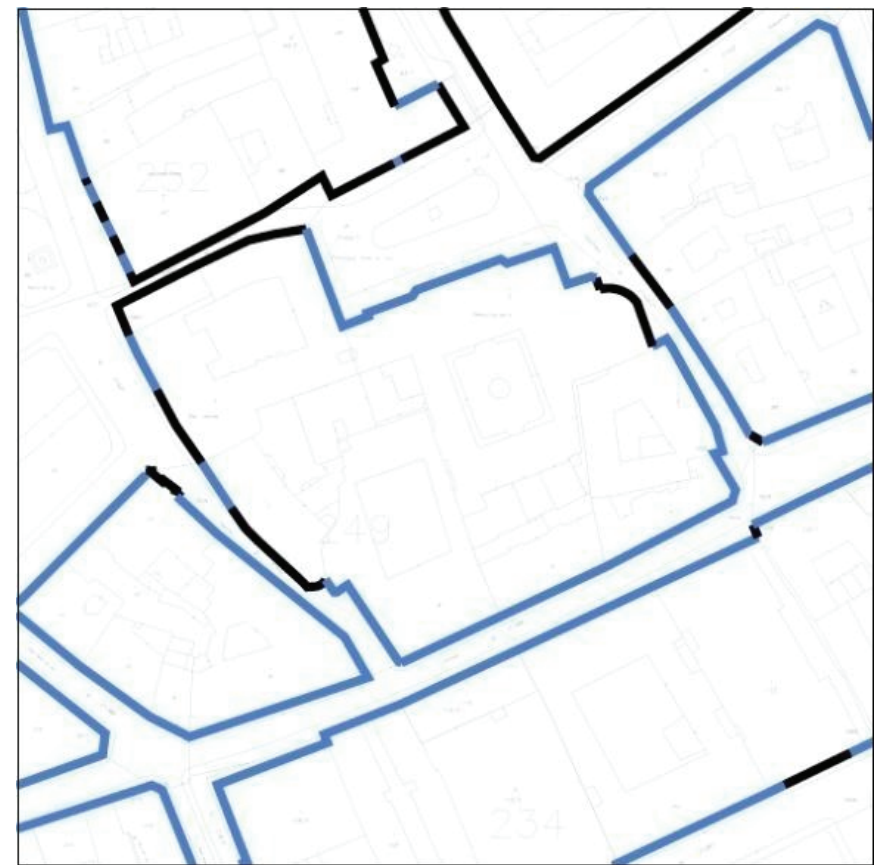

Fig. 4 Example of mapping the active façades.

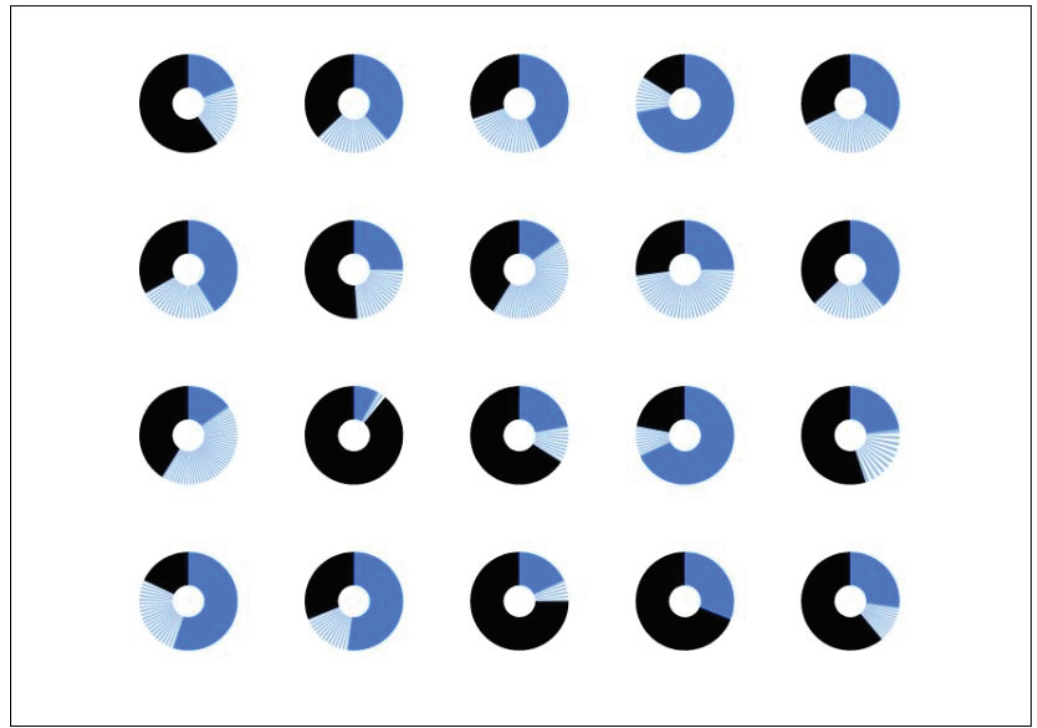

Fig. 5 Ratio of active, potentially active and passive ground floor.

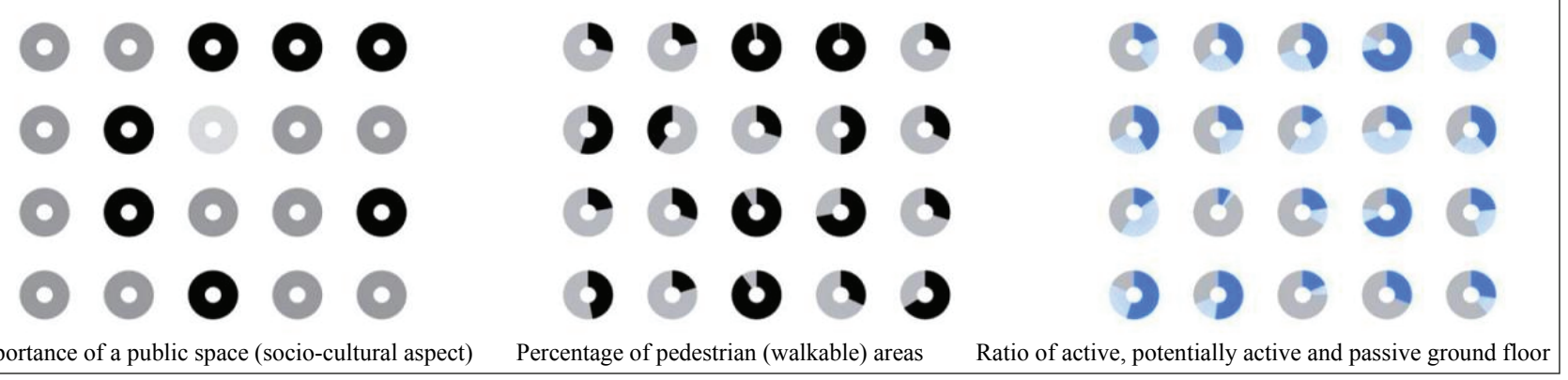

Fig. 6 Importance, percentage of pedestrian areas and percentage of active façades. 


\section{Findings and Conclusions}

Returning back to those big goals stated earlier, it must be said that this part of the research is only a small element in quite a great system of a well lived and living city paradigm, however, not discovered completely yet. The other fact is that history, database, directing and political rules are just being formed.

Speaking about the smaller goals where the above mentioned tools and elements were used, there have been done some findings about the mutual responding values analyzed in the city.

Importance, percentage of pedestrian areas and percentage of active façades, three characteristics were put into a matrix (Fig. 7) to find out repeating phenomena/extraordinary examples of a place. As first, the importance was taken as a leading factor and the other schemes were adapted; In the second comparing matrix, the middle column of percentage of pedestrian areas was leader; and in the third step the scheme was adapted to the percentage of active façades. The point is in putting the information in a more simple way of evaluation.

In the first comparing matrix, it was found out that half of the nationally or internationally important squares have half of the surface dedicated to pedestrian, from which one has got remarkably little percentage of surface dedicated to them and at the same time, the ration of potentially active façades is low (Rybné Námestie, 4th row, 3rd column). It could be a consequence of a bridge with flyovers built roughly in the historical medieval urban structure.

Only half of squares with city/regional importance have at least half of the surface walkable and except two of them, which have a good potential of increasing the percentage of active façades. One of them is special for being almost whole pedestrian while having only a third of façades active or potentially active (Námestie M. Benku, 3rd row, 3rd column). That may be a result of absent enclosing buildings on two sides of the nearly rectangular square.
In the second comparing matrix it was understood that squares with the highest rate of pedestrian area are of national and city importance in ratio of 1:1, however without any direct context. Out of these, an average potential of active façades is $50 \%$ which is a good value.

Almost all squares with less than a third pedestrian area have a potential of active façades higher than $50 \%$. This says, squares with relatively good quality of ground floor located have more potential in being active façades in contrast with what could be expected in a place with traffic character. One special public space (Námestie Alexandra Dubčeka, 3rd row, 1st column) has not only got a little area for pedestrians but also remarkably low potential of active façades. It is caused by monumental architecture of castle fortification and the building of National Council with high pedestal of staircase.

The third comparing matrix shows that public spaces with best activity in parterre are rather of city than of a national importance. There are also squares of international importance with the lowest potential of activity in ground floor. One special public space (Jakubovo Námestie, 2nd row, 3rd column) has got greater potential of active façades than some of the national importance, however still not reached.

It is clear from the given results that there still are parts of the research that could be done more analytically, more precisely, and in a slightly different way. In general, the cooperation of university and chief architect could be supported by a research institute as an in-between-element for coordination and direction of the effort given (e.g., at workshops, one day events such as an on-site sociological investigation).

From the academic point of view, some other topics are getting opened. For example, the abandonment as important predictable but undefined problem should be defined and divided into more types like emptiness in places as a result of people not going through and not staying in a place; daily or seasonal emptiness acting like time-homogeneity that can be richly changed by 


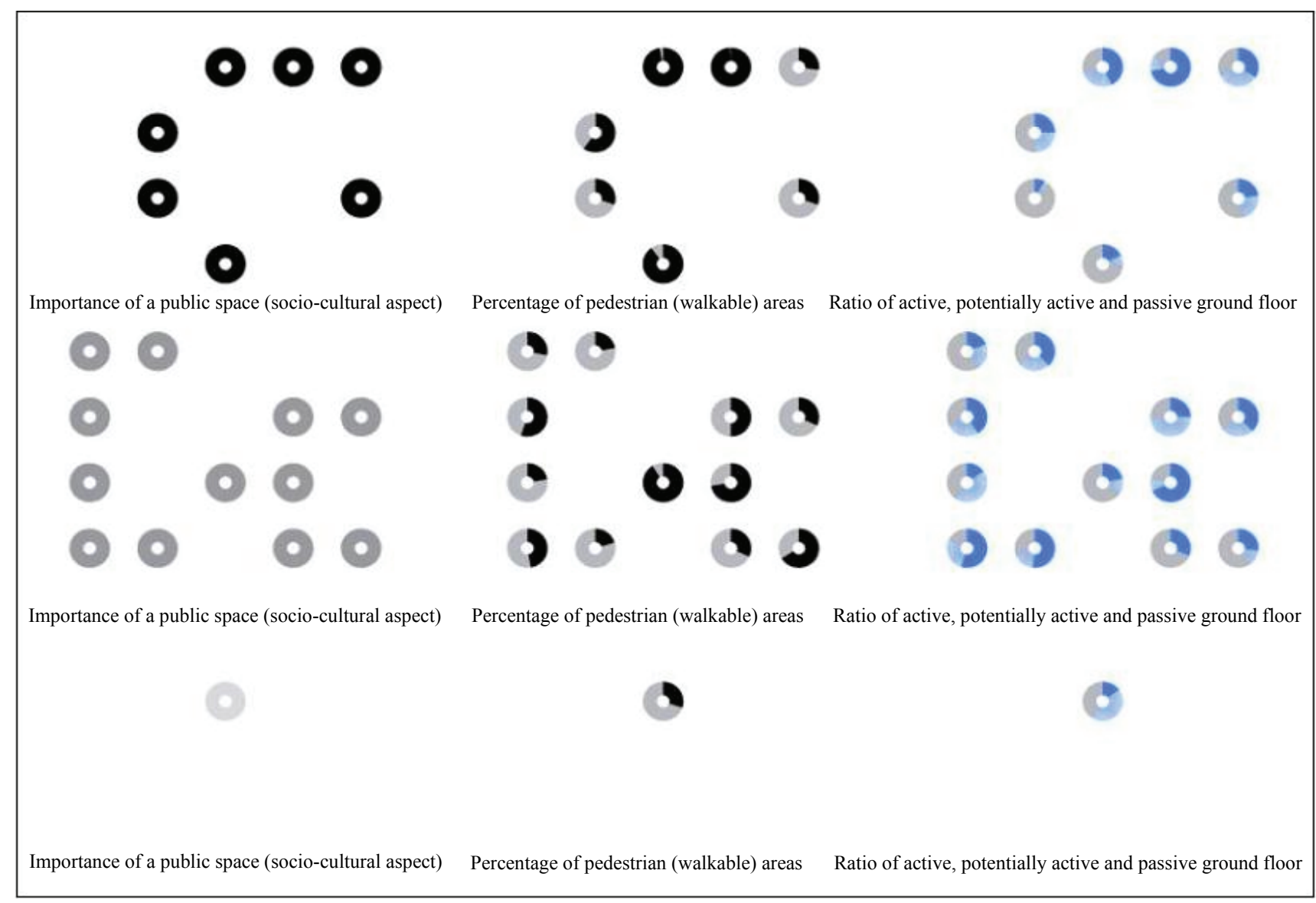

Fig. 7 Example of a comparing matrix, No. 1.

events, concerts, activities of different kind; building abandonment as a result of bad city's self-governing policy tolerating the owners and even its own branches responsible for pending and postponing letting the building be rented or bought and relived.

For the Office of Chief Architect of Bratislava, it is currently very important to work on and finish the manual of public spaces concerned with sub-topics as follows: system of public spaces and its finishing; temporary and small architecture; public advertisement; regulations of new and reconstructed architecture; events in the public spaces and its administrations; typology of street corridors; rules for using and placing components.

\section{References}

[1] Gehl, J., and Gemzøe, L. 2004. Public Spaces, Public Life. Copenhagen: Danish Architectural Press. ISBN: 978-87-7407-305-5.
[2] Gehl, J. 2012. Cities for People. Brno: Environmental Partnership. ISBN: 9788026020806.

[3] Melkova, P., 2014. "Manual for Designing Public Spaces in the Capital Prague." Prague Institute for Planning and Development. Accessed September 9, 2015. http://manual.iprpraha.cz/uploads/assets/STRATEGIE-M ANUAL_brochure.pdf.

[4] Schulz, C. N. 2010. Genius Loci. Translated by Kratochvíl, P., and Halík, P. Prague: Dokořán. ISBN: 9788073633035.

[5] Vitková, L., and Bindzárová, A. 2015. "Public Spaces as the Factor of Urban Identity: Case Study of Bratislava, Definite Space-Fuzzy Responsibility." In Proceedings of 29th Annual AESOP (Association of European Schools of Planning) 2015 Congress, 1046-58.

[6] Vitková, L'. 2015. "The Public Spaces Methods Assessments. The Selected Squares Analyses in Bratislava." ALFA (Architektonické listy Fakulty Architektúry) 1: 22-33. ISSN: 1135-2679.

[7] Sitte, C. 1995. City Planning According to Artistic Principles. Translated by Buriánek, V. Zlín: Arch. ISBN: 80-901608-1-6.

[8] Gehl, J. 2000. Life between Buildings: Using Public Space. 
Translated by Blažek, K. Copenhagen: Danish Architectural Press. ISBN: 80-85834-79-0.

[9] Krier, R. 1975. "Urban Space." Academy Editions. Accessed July

29 , 2015. http://www.sze.hu/ nemethi/V\%C1ROS\%20szakirodalo $\mathrm{m} /$ rob\%20krier\%20-\%20urban\%20space.pdf.

[10] Kolcunová, P. 2015. "Intensification of Housing Estates: Changes in Spatial Structure of Mass-housing Estates within the Context of Eastern Europe." ALFA (Architektonické listy Fakulty Architektúry) 2015: 68-77. 